\title{
TECHNOLOGY OF PRODUCING REINFORCED CONCRETE COLUMNS OF CIRCULAR CROSS-SECTIONAL AND INVESTIGATION OF THEIR STRAIN-STRESS STATE AT TRANSVERSE-LONGITUDINAL BENDING
}

\author{
Ivan L. Rogovskit ${ }^{a}$, Liudmyla L. Titova ${ }^{a}$, Oleksii O. Davydenko ${ }^{b}$, \\ Viktor I. TrokhaniaK ${ }^{c, *}$, Oleksandra M. TrokhaniaK ${ }^{d}$ \\ ${ }^{a}$ National University of Life and Environmental Sciences of Ukraine, Mechanical and Technological Faculty, \\ Department of Occupational Safety and Environmental Engineering, Heroiv Oborony Str., 15, 03041 Kyiv, \\ Ukraine \\ ${ }^{b}$ National University of Life and Environmental Sciences of Ukraine, Design and Engineering Faculty, \\ Construction Department, Heroiv Oborony Str., 15, 03041 Kyiv, Ukraine \\ ${ }^{c}$ National University of Life and Environmental Sciences of Ukraine, Education and Research Institute of \\ Energetics, Automation and Energy Efficiency, Heat and Power Engineering Department, Heroiv Oborony Str., \\ 15, 03041 Kyiv, Ukraine \\ ${ }^{d}$ National University of Life and Environmental Sciences of Ukraine, Faculty of Design and Engineering, \\ Department of Engineering Reliability, Heroiv Oborony Str., 15, 03041 Kyiv, Ukraine \\ * corresponding author: trohaniak.v@gmail.com
}

\begin{abstract}
The paper presents a method of producing Circular Cross-Section Columns (CCSC), which can provide sufficiently precise dimensions, with longitudinal reinforcement securely fixed in special plugs. An investigation procedure for determining the capacity of CCSC at all the stages of their loading with eccentric pre-stressing has been presented. Based on the conducted experimental work, load carrying and deformation parameters of the strain-stress state of reinforced concrete CCSC have been obtained. The investigation results make it possible to define calculation prerequisites and fracture criteria of the deformation method of calculating compressed-bent elements of CCSC at transverse bending and reinforcement deformation below the yield point.
\end{abstract}

KEYWORDS: Circular cross-section, strain-stress state, transverse force, deformation method.

\section{INTRODUCTION}

The use of optimal reinforced concrete compressedbent elements of CCSC in the form of columns of frame buildings, bored piles, retaining walls, landslide protection structures, which can take up substantial lateral earth pressure, is restricted due to the lack of a sufficient amount of experimental and theoretical research of strain-stress state under the action of transverse force and longitudinal compression force. The influence of longitudinal reinforcement dowel action at multi-row reinforcement and the influence of longitudinal reinforcement on load bearing capacity according to transverse force are the problems, which have not been investigated. In building regulations for calculating the resistance of the oblique sections of reinforced concrete elements [1], empirical and semiempirical dependences are used, which does not make it possible to take into complete account the influence of the main factors on load bearing capacity across an oblique section. The deformation method [10 15] of calculating load bearing capacity of the normal sections of CCSC is grounded on clear physically based prerequisites and represents the physics of the process rather precisely, making it possible to develop a calculation basis for determining load bearing capacity according to the transverse force of the above mentioned sections [16 20]. Thus, the development of the deformation method of the assessment of strain-stress state and load bearing capacity of compressed-bent elements of CCSC is important in order to increase the reliability of engineering buildings and structures according to a valid diagram of vertical and horizontal loading, including accidental exposures.

\section{MATERIAL AND METHOD}

In order to investigate reinforced concrete CCSC, models of these columns with distributed reinforcement for taking up vertical and horizontal loading were made (Fig. 1). Six reinforcement bars $\varnothing 10$ A400C were used as longitudinal reinforcement and wires $\varnothing 4$ $\mathrm{BI}$ were used as a transverse reinforcement. The experimental models were made as CCSC, being $2 \mathrm{~m}$ in length and $190 \mathrm{~mm}$ in diameter. The models were prepared in moulds made of plastic pipes with $200 \mathrm{~mm}$ in diameter.

The longitudinal reinforcement bars were put into designed holes in the end plugs of the pipes aimed at fixing a uniform spacing of longitudinal bars around the circumference and forming a concrete cover in a column end, Fig. 2a. In order to create a space 

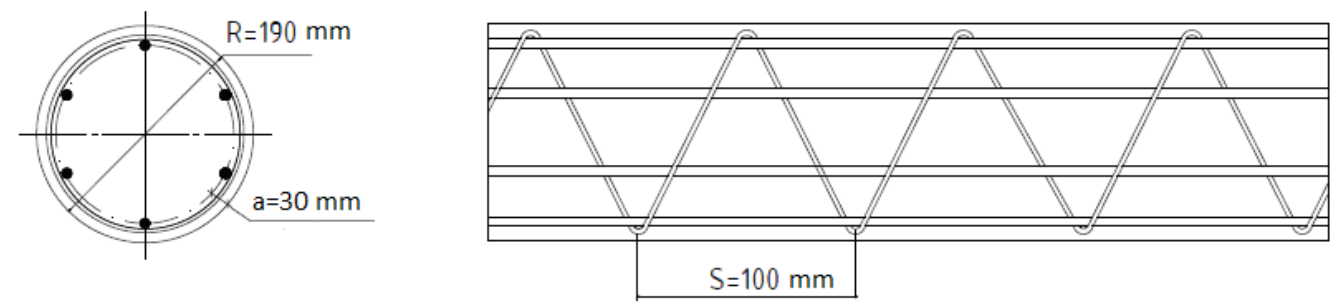

Figure 1. Models of reinforced concrete CCSC.

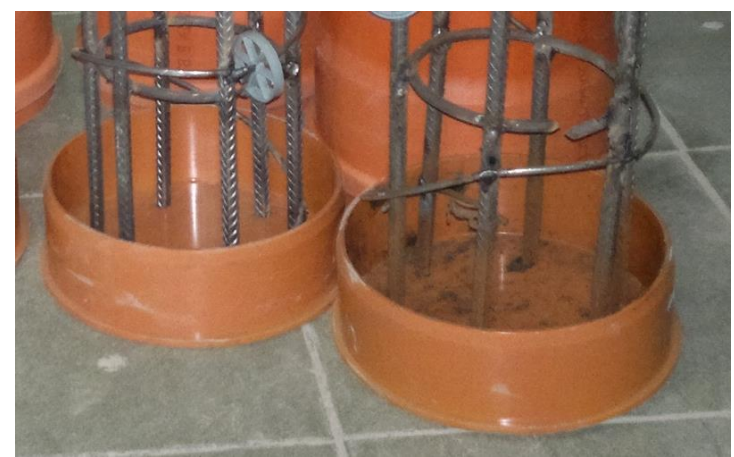

(A).

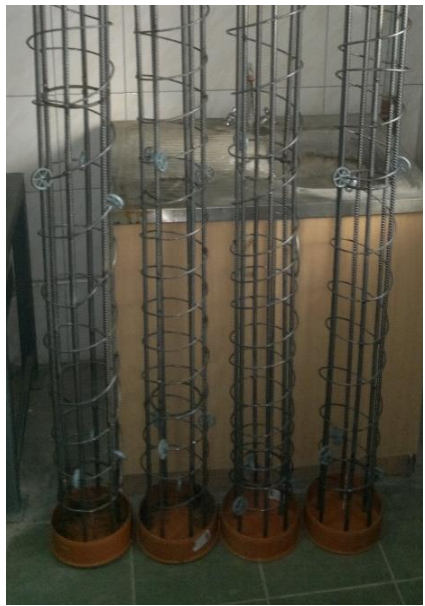

(C).

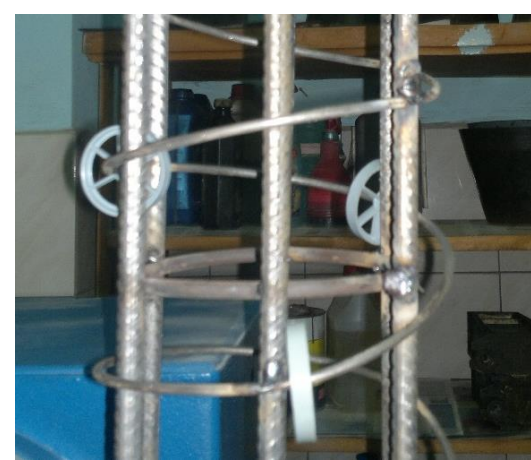

(B).

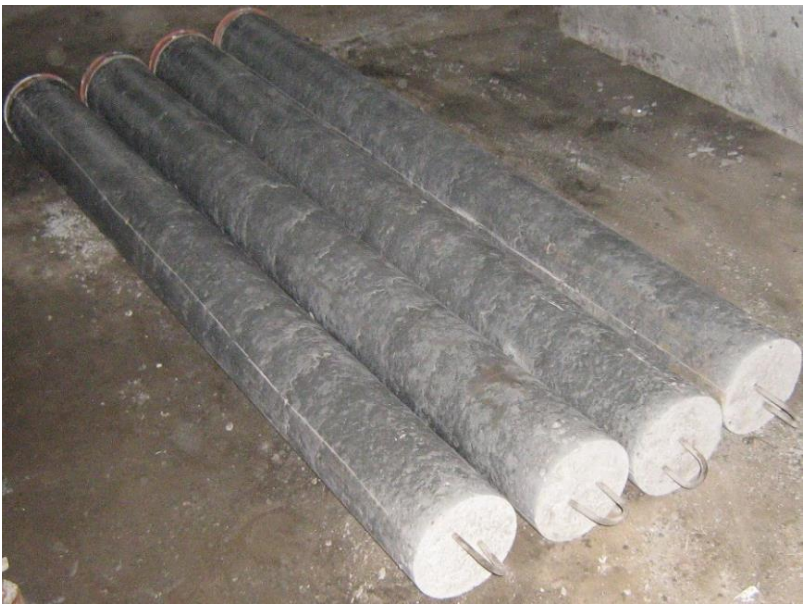

(D).

Figure 2. The parts of a reinforced concrete CCSC and the fabricated models.

frame and fix the bars in bays on the inside of a frame, special rings made of plain rebar $\varnothing 8 \mathrm{BI}$ were arranged in a number of three rings per one column. The rings were positioned at the column ends and in the column centre. The concrete cover was fixed in the column centre with the help of special plastic spacers. Fig. $2 \mathrm{~b}$ presents the arrangement of rings and spacers. Steel rings were welded to longitudinal bars by electrodes $2 \mathrm{~mm}$ in diameter. A spiral reinforcement was fabricated from a steel wire. The spiral was stretched at the even pitch of $100 \mathrm{~mm}$ and was welded to the longitudinal bars of a column frame. As a result, the space frames presented in Fig. 2c have been obtained.

The fabricated space frames were placed into plastic pipes, which were used as an outer form. The secure plug fixing was provided by a sealing rubber pad placed in the grooves of standard pipe plugs. Lifting loops were arranged on one of the column ends and put behind the inner steel rings for a better anchorage.

The depth of the concrete cover was equal to $30 \mathrm{~mm}$, which met the requirements specified for CCSC as well as the recommendations on designing reinforced concrete frames [21]. Transverse spiral reinforcement's spacing was determined based on the design requirements for a confinement reinforcement of columns.

A casing was made in the form of a space frame of reinforcement $\varnothing 20 \mathrm{~A} 400 \mathrm{C}$. It was used forconcreting with vertical fixing of a holder of four plastic pipes, which made an outer form and were filled with steel frameworks.

In order to prepare a concrete mix, M 400 cement, granite macadam $5 \div 10 \mathrm{~mm}$ in size and Dnipro river fluvial sand were used. The mix was compacted using a vibrating table. The vibration magnitude was deter- 


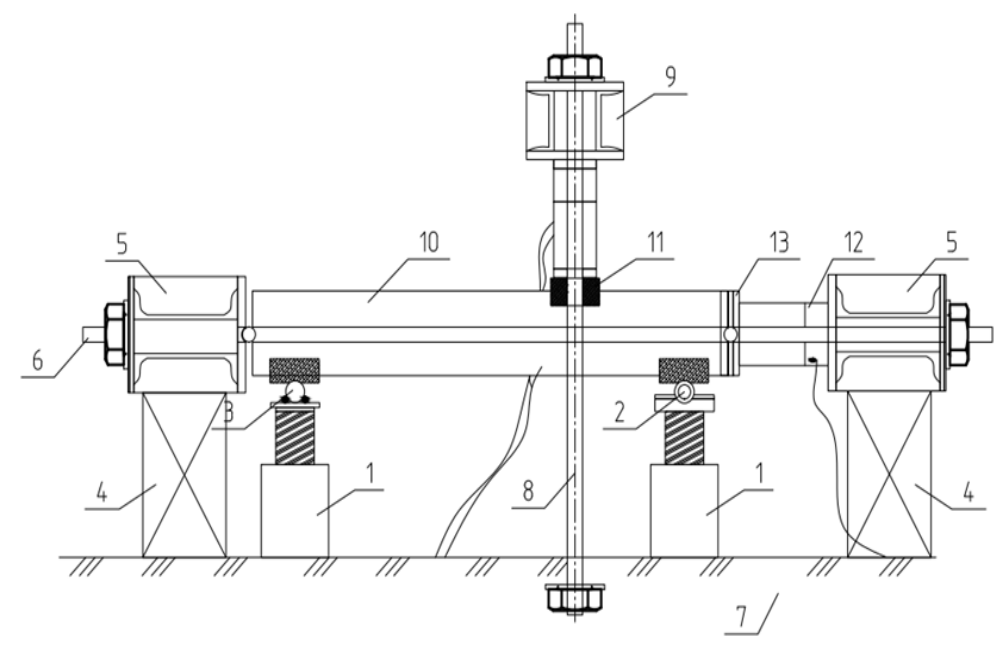

(A).

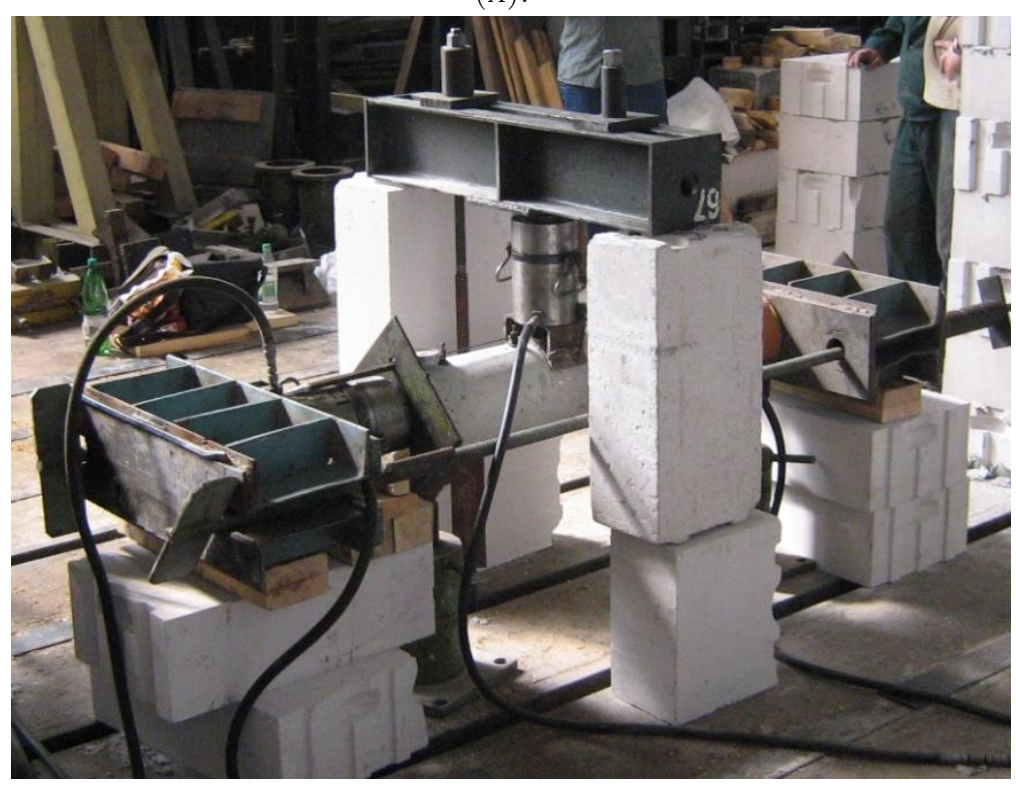

(B).

FIGURE 3. Diagram (a) and general view (b) of the experimental plant for testing CCSC at longitudinal-transverse bending.

mined by mix plasticity and lasted for 10-15 minutes. A cone slump (OK 12) was chosen for more sufficient filling of pipes with concrete, taking into consideration the spiral reinforcement and additional inner rings $\varnothing 6 \mathrm{BI}$ used for making a space frame in each pipe of the outer form. The process of making the models of CCSC was the following: a casing with a form made of pipes was arranged on a vibrating table and the pipes were filled with concrete in small batches followed by a short vibration after every concrete batch.

At the same time, a bridge crane supported a holder of the pipes of CCSC during the vibration by means of a choker hitch, which was attached to the hinge of a casing. The concrete mix compacting was stopped after the cement was found bleeding on the surface of a top column end. The concrete mix surplus was removed from the top column ends after the vibrocompaction.
After removing the form with a circular saw, the column models were kept in moist saw dust for 7 days and, then, they were kept in a temperature range between 15 and $20^{\circ} \mathrm{C}$ and moisture conditions of 90$100 \%$ during 28 days.

Fig. 2d presents the models of reinforced concrete CCSC, which are reinforced by means of the longitudinal load bearing reinforcement and transverse spiral reinforcement.

The set of columns $\mathrm{K}-1(2,3)$ used for carrying out the experiment, included three samples with longitudinal pre-compression force of not more than $0.25 P_{s t}$. The equal to $0.04 \mathrm{~m}$, which approximately corresponded to the distance from the central geometrical axis of the section to the axis that passes through the centre of the triangular area of the beamcolumn bearing. The value of the pre-stressing force by hydraulic jack was $150 \mathrm{kN}$. Longitudinal bending of 
columns caused by the pre-stressing force was directed away from the subsequent transverse bending due to the action of transverse force.

The diagram of the experimental plant is presented in Fig. 3 .

A sliding support 2 and a fixed support 3 were mounted on special steel screw jacks 1 that made it possible to place column models by a level. The supports were made of steel pipe half rings, which were equal in size to the diameter of a column. The half rings were placed and fixed in channels, which were attached to $\varnothing 30 \mathrm{~mm}$ iron rods. On the right side and on the left side of steel screw jacks 1, there were special supporting fixtures 4 arranged for a longitudinal loading crosspiece 5 . The crosspiece 5 consisted of two channels with intermediate stiffening ribs and plates welded to the legs of the channels. Openings were made in the plates in order to arrange tension bars 6 , which were fastened by nuts and washers. In the grooves of the reinforced floor 7 , there were vertical tension bars 8 attached with their top ends passing through the openings of a longitudinal loading crosspiece 9 and they were fastened by nuts and washers. The crosspiece 9 was reinforced by stiffening ribs. The experimental model of a column 10 was mounted on a hinged movable 2 and immovable 3 supports. According to the diagram of transverse bending, at the point of transverse load application, a semi-holder 11 consisting of a half ring made of a steel pipe, which is equal in size to the diameter of a circular column, that is placed in a channel, similar to lower supports, was mounted by cementing on the experimental column 10 at the distance of $2 \varnothing$ from the left support. The channel had a groove for a ball-joint hinge. A hydraulic jack for a vertical load application was arranged between the crosspiece 9 and the semi-holder with a joint hinge 11. A hydraulic jack for a horizontal load application 12 was arranged between the crosspiece 5 and the column 10. The eccentricity of the horizontal load application was set by the means of the displacement of a jack and a plate by a ball-joint hinge 13 .

The column loading was conducted by the means of the force transmitted by hydraulic jacks from the stationary pressure equipment (hydraulic power station). The force was recorded according to the pressure equipment scale. The levelling of column models and crosspieces was carried out with the help of a level.

In order to assess column deformations, mechanical extensometers of type 1 with the value of division being $0.001 \mathrm{~mm}$ and $200 \mathrm{~mm}$ spacing, which were attached to the concrete surface of the columns by holders - benchmarks, were used. In order to attach the holders - benchmarks, cyacrine-based adhesive was applied. Deflections were measured using a dial gauge with the value of division being $10^{-2} \mathrm{~mm}$, which was attached on a bracket and positioned in the area of transverse column bending under the point of a transverse force application. The layout of transverse deformation gauges is presented in Fig. 4

Prior to the experiment, column centring was conducted. For this purpose, a column was loaded. The load did not exceed elastic strain (up to $30 \times 10^{-5}$ units of longitudinal strain in the compression area of the concrete). After the loading, the correspondence of the longitudinal strain on column sides to the fixation of a model axis in the plane of transverse-longitudinal bending was checked. If the indicator reading on the column sides was the same or close to the strain value (divergence $\pm 5 \%$ ), a column was considered to be centred. Otherwise, a column was unloaded, a hydraulic jack and a crosspiece 5 were moved in such a way as to adjust the reading of the instruments installed on the sides.

In the process of column model loading, the force transmitted to the model, concrete longitudinal deformations on compression and tension sides, bending, the highest and fracture load were measured. The fracture load was assumed to be the load, which was equal to the peak strain in the compression area of the concrete. Fixation of the highest load and fracture load, which was equal to the peak strain in the compression area of the concrete, was conducted according to the load-bending relation.

Model loading was applied in increments relative to the strain with curing periods after every increment. A curing period was equal to the time needed for taking the reading, namely, equal to approximately 4...5 min. At every load application, incremental relative longitudinal strain in the compression area of concrete was equal to $25 \times 10^{-5}$ units of relative strain at every increment. The columns were tested at the age of 130 days.

\section{RESUlt}

Based on the experimental research conducted at transverse bending under pre-stressing conditions with eccentricity relative to a column axis, load and deformation parameters of the stress-strain state of reinforced concrete CCSC have been obtained.

The results of testing the columns reinforced by the longitudinal and spiral reinforcement are presented in Table 1. The parameters under study, which are shown in the table, are the following: the highest values of longitudinal force, moment, curvature, longitudinal compression and tension strain of concrete, which was determined in the bay area of the section, and deflections.

According to the results of model testing, namely testing K- $1(2,3)$ set of columns, at transverse bending with longitudinal pre-stressing, shown in Table 1 the corresponding relations have been plotted, " $P-\varepsilon_{c}$ ", "P $P \varepsilon_{c t} "$, " $Q-\chi ", ~ " M-\chi "$, Fig. 5

" $P-\varepsilon_{c}$ " relations presented in Fig. 5 characterize the strain of a compression column face in the process of pre-stressing and the relations shown in Fig. 6 correspond to the stain of a tension column face at 


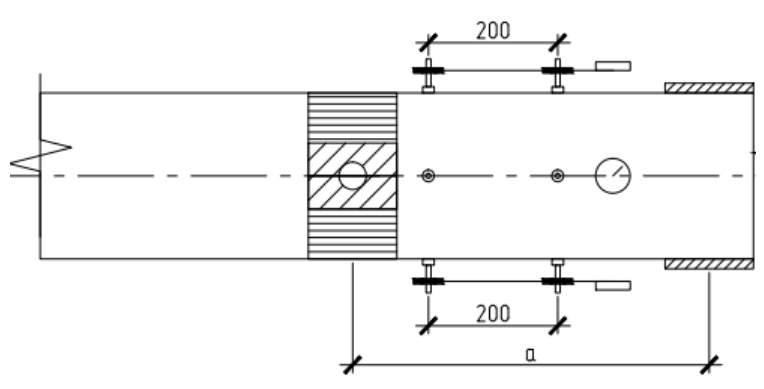

(A).

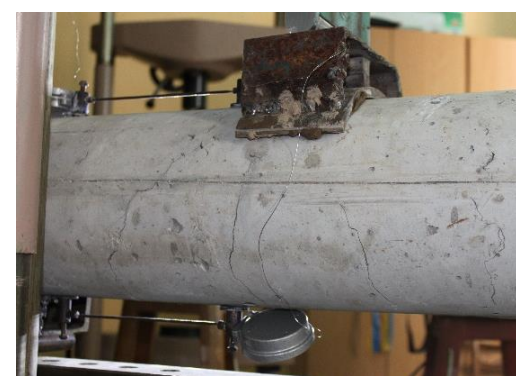

(B).

Figure 4. Layout (a) and general view (b) of the equipment used in the experimental research.

\begin{tabular}{|c|c|c|c|c|c|c|}
\hline $\begin{array}{l}\text { Column } \\
\text { number }\end{array}$ & $\begin{array}{l}\text { Transverse } \\
\text { force }\end{array}$ & $\begin{array}{l}\text { Bending } \\
\text { moment }\end{array}$ & $\begin{array}{c}\text { Longitudinal } \\
\text { compressional } \\
\text { strain } \\
\text { of concrete }\end{array}$ & $\begin{array}{c}\text { Longitudinal } \\
\text { tension } \\
\text { strain } \\
\text { of concrete }\end{array}$ & $\begin{array}{l}\text { Column } \\
\text { curvature }\end{array}$ & $\begin{array}{l}\text { Column } \\
\text { deflection }\end{array}$ \\
\hline & $\begin{array}{c}Q_{\max } \\
\mathrm{kN}\end{array}$ & $\begin{array}{c}M_{\max } \\
\mathrm{kN}\end{array}$ & $\begin{array}{c}\varepsilon_{c \max } \\
10^{-5}\end{array}$ & $\begin{array}{c}\varepsilon_{c t \max } \\
10^{-5}\end{array}$ & $\begin{array}{c}\chi_{\max } \\
\mathrm{m}^{-1}\end{array}$ & $\begin{array}{c}f_{\max } \\
10^{-3} \mathrm{~m}\end{array}$ \\
\hline K- 1 & 69.026 & 23.46 & 312 & 301 & 0.0322 & 11.15 \\
\hline K- 2 & 73.84 & 25.10 & 311 & 276 & 0.0277 & 9.96 \\
\hline K- 3 & 70.18 & 23.86 & 298 & 283 & 0.0305 & 9.61 \\
\hline $\begin{array}{l}\text { Average } \\
\text { value } \\
\mathrm{K}-1(2,3)\end{array}$ & 71.01 & 24.14 & 307.0 & 287.0 & 0.0301 & 10.24 \\
\hline $\begin{array}{l}\text { Coefficient } \\
\text { of variation } \\
v\end{array}$ & 3.53 & 3.51 & 6.1 & 7.3 & 9.6 & 7.8 \\
\hline
\end{tabular}

TABLE 1. Results of model testing at longitudinal-transverse bending.

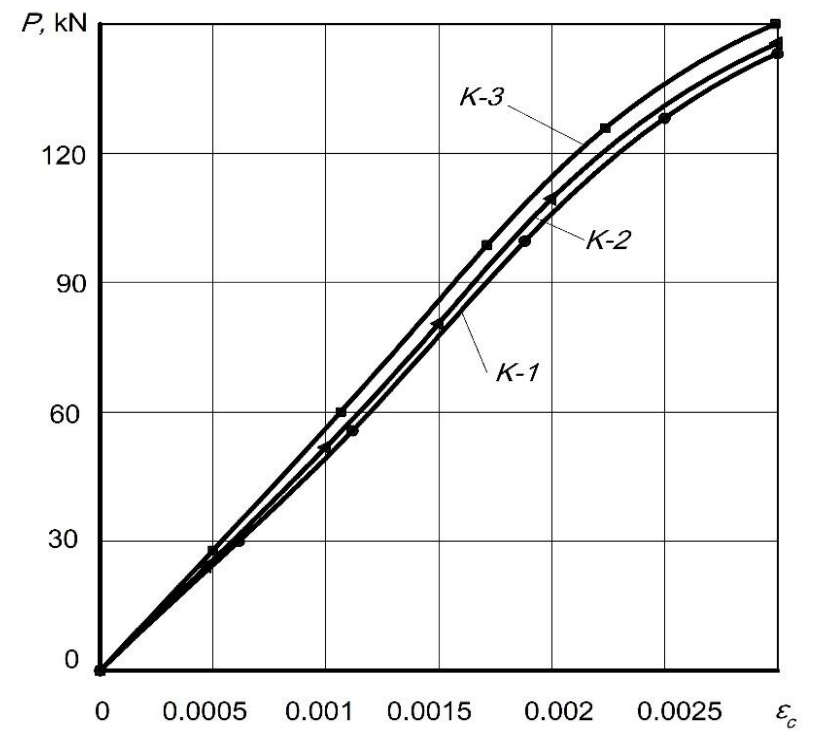

FiguRE 5. " $P-\varepsilon_{c}$ " relations for $\mathrm{K}-1(2,3)$ set of columns.

eccentric pre-stressing. According to the diagrams, the values of concrete compression strain of the columns at eccentric pre-stressing do not exceed the elastic values.

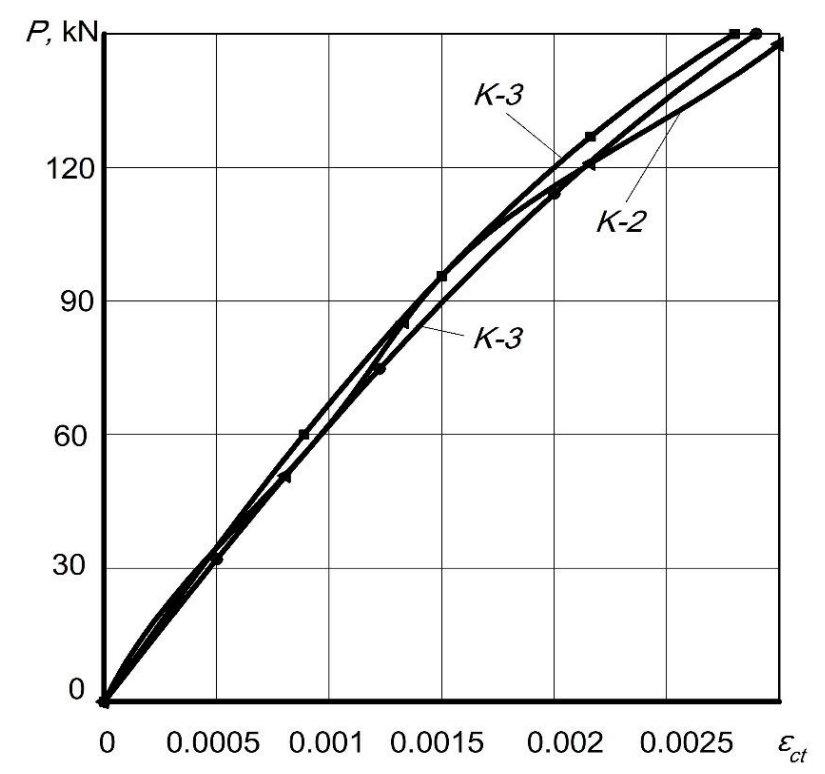

Figure 6. " $P-\varepsilon_{c t}$ " relations for K- $1(2,3)$ set of columns.

The investigation results show an insufficient divergence in the measures of strain on compression and tension faces, here, the average value of compression strain after the longitudinal eccentric column 


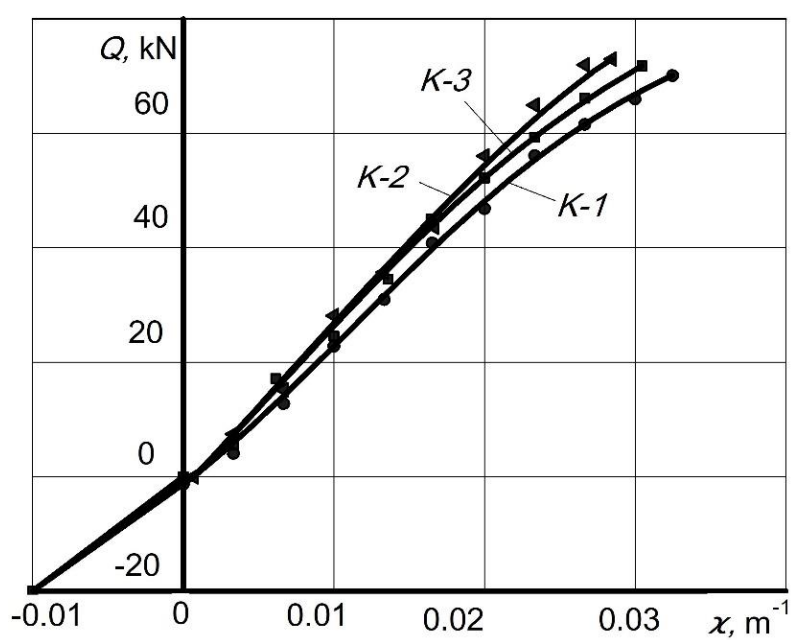

Figure 7. " $Q-\chi$ " relations of the CCSC under the conditions of longitudinal-transverse bending at $a=$ $2 \varnothing$ section bay, K- $1(2,3)$ set.

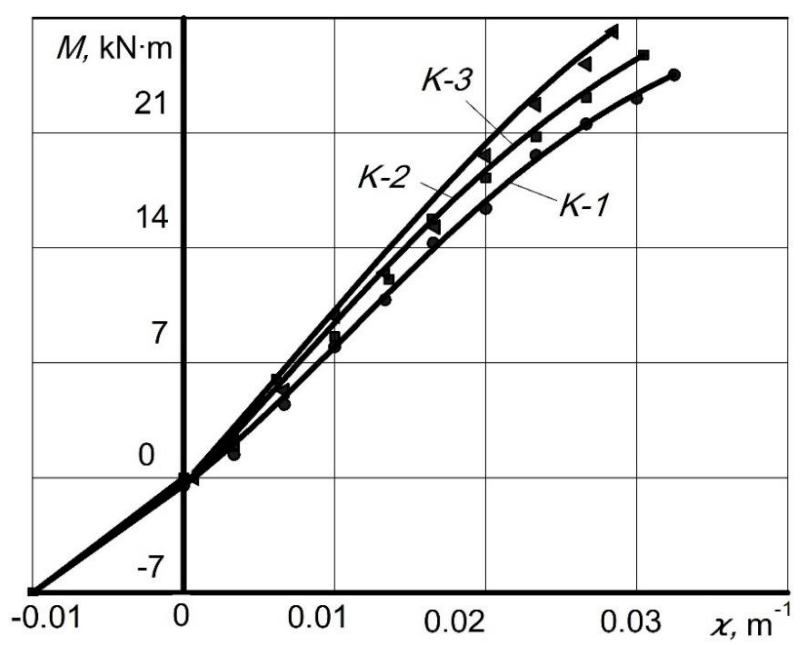

FiguRE 8. " $M-\chi$ " relations of the CCSC under the conditions of longitudinal-transverse bending at $a=$ $2 \varnothing$ section bay, K- $1(2,3)$ set.

pre-stressing practically does not exceed the elastic values.

According to the diagrams, pre-stressing $(D=150$ $\mathrm{kN}$ ) at the initial stage of the investigations caused a certain inverted curvature of a column, Fig. 7. 8 ,

As a result, a pre-stressed column fracture takes place along an oblique section with a longitudinal concrete splitting in the compression area, Fig. 9 .

An eccentric compression on one side loads, in addition, the compressed column area, thus, it increases concrete compression strain and it contains oblique crack growth by preventing the turn of one section part relative to the other one, as it usually happens at normal transverse bending. It is worth mentioning that the eccentricity of the longitudinal force application was chosen to be $e=0.04 \mathrm{~m}$ for this experiment. That is why it is believed that, if there is longitudinal compression force applied with a greater eccentricity, which is directed back from the following transverse bending, the influence of the eccentric pre-stressing on load carrying capacity according to transverse force will be greater.

As for the dowel action of the transverse reinforcement at a multi-row reinforcement of the CCSC under the conditions of transverse bending and eccentric prestressing, such an action takes place after the yield point is reached in the longitudinal bars. They are the most distant from the compression area at the last stages of deformation. After the beginning of the critical oblique crack opening in the bars located in the tension area higher in the section. This is similar to the case of transverse bending (without pre-stress).

It is worth mentioning that the dowel action in longitudinal tension reinforcement at the point, where it is intersected by an oblique crack, is significantly lower in case of the spiral reinforcement and is greatly increased in case there is a rupture of the indicated spiral reinforcement bars, Fig. 10

This results in the increase of the transverse shear of one concrete part relative to the other one, which are split by an oblique crack. Thus, the dowel action of the longitudinal tension reinforcement in terms of containing transverse shear of a CCSC takes place after the beginning of the oblique section fracture, the attainment of the yield point or the rupture of spiral reinforcement and can be used for the assessment of the design survivability only.

\section{Conclusions}

In order to provide sufficiently precise dimensions of CCSC, a method of producing columns in a mould made of plastic pipes $200 \mathrm{~mm}$ in diameter with longitudinal reinforcement securely fixed in special plugs is presented. Here, the use of a casing made it possible to make a set of models, in which the pipes were filled with the concrete from one batch.

The suggested investigation technique allowed for obtaining valuable data on load bearing capacity of the CCSC at all the stages of their loading, when testing reinforced concrete elements with eccentric pre-stressing.

The conducted research on testing CCSC under the conditions of transverse bending with eccentric prestressing corresponds to the actual structural element design. Based on the experimental investigation conducted at transverse bending under the conditions of pre-stressing with the eccentricity relative to a column axis, load carrying and deformation parameters of the stress-strain state of reinforced concrete CCSC have been obtained.

The dowel action of the longitudinal tension reinforcement, in terms of containing transverse shear of a CCSC, takes place after the beginning of the oblique section fracture, the attainment of the yield point or the rupture of the spiral reinforcement and can be used for the assessment of the design survivability only. 


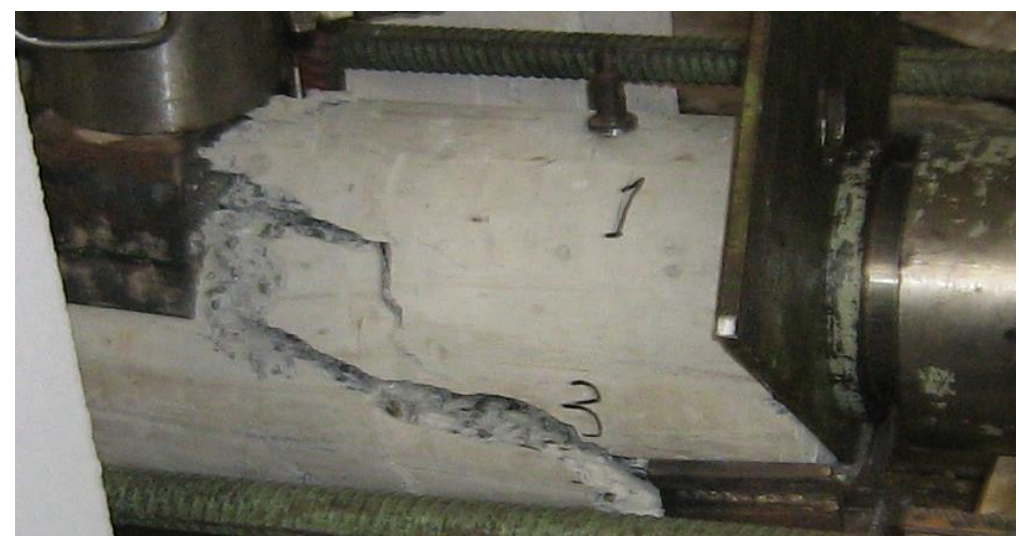

Figure 9. Pre-stressed column fracture along an oblique section.

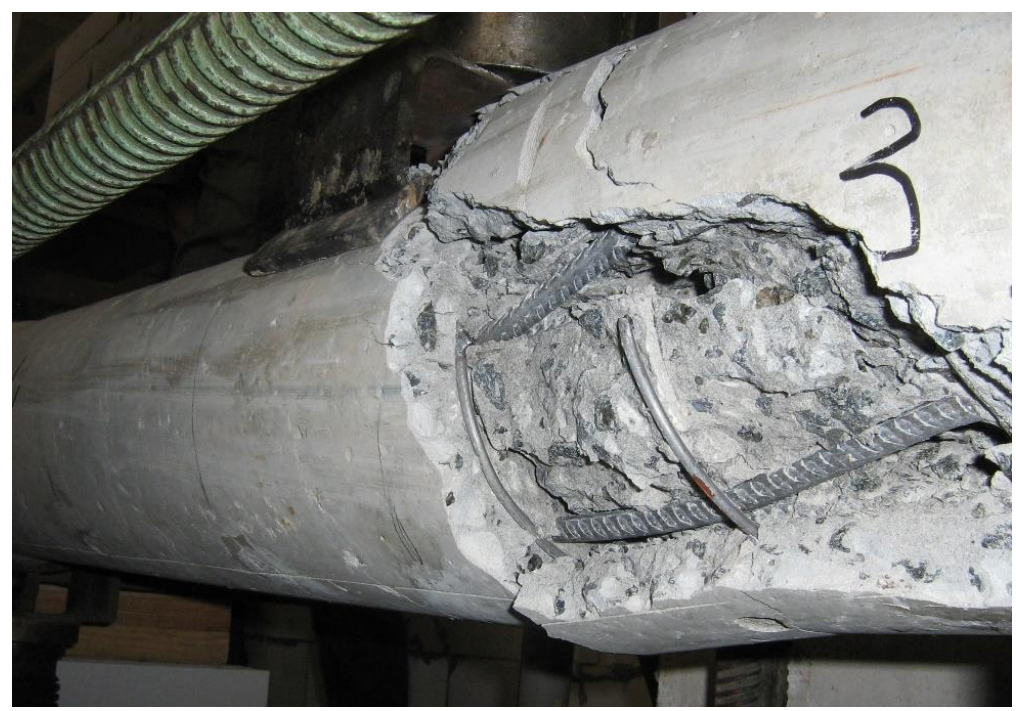

FIGURE 10. Dowel action in longitudinal tension reinforcement in terms of containing transverse shear of a CCSC.

The obtained results of the experimental research make it possible to develop calculation prerequisites and fracture criteria for the deformation method of calculating compressed-bent elements of CCSC at transverse bending and reinforcement strain below the yield point.

\section{REFERENCES}

[1] . Bambura, V. Dorohova. Bearing ability of reinforced concrete elements of a circular section according to the deformation model. Building constructions 74:180-188, 2011.

[2] EN 1992-1-1-2011. Eurocode 2: Design of concrete structures - Part 1-1: General rules and rules for buildings. standard, 2011.

[3] S. Anandan, S. Fakrul, R. Abad, A. Babaker. Characteristics of steel fibre reinforced high strength concrete beams: Efficiency in size reduction for flexure. Engineering Journal 22(4):191-208, 2018. DOI:10.4186/ej.2018.22.4.191.

[4] F. Vogel, O. Holcapek, P. Konvalinka. Response of high-performance fibre reinforced concrete reinforced by textile reinforcement to impact loading. Acta Polytechnica 56(4):328-335, 2016. DOI:10.14311/AP.2016.56.0328.
[5] H. Karim, M. Sheikh, M. Hadi. Load and moment interaction diagram for circular concrete columns reinforced with gfrp bars and gfrp helices:. Journal of Composites for Construction 21(1):04016076, 2016. DOI:10.1061/(ASCE)CC.1943-5614.0000737.

[6] S. Li, W. Lu, W. Qingfei, et al. Study on failure mechanism and mechanical properties of casing joints of square steel confined concrete arch. Engineering Failure Analysis 92:539-552, 2018. DOI:10.1016/j.engfailanal.2018.05.011.

[7] V. Popov, A. Sapunova. Investigation of stress-strain state of fibrous concrete bent elements of a trapezoidal profile with combined reinforcement. Industrial and Civil Construction 9:15-20, 2015.

[8] L. Blesák, V. Goremikins, F. Wald, T. Sajdlová. Constitutive model of steel fibre reinforced concrete subjected to high temperatures. Acta Polytechnica 56(6):417-424, 2016. DOI:10.14311/AP.2016.56.0417

[9] H. Xiong, B. Li, J. Jiang. Applicability of stress-strain model for frp-confined concrete cylinders. Journal of Zhejiang University Engineering Science 49(12):2363-2375, 2015.

[10] H. Shyshko. Stress-strain state and rigidity of a bent round rod with cracks in the stretched zone. Building construction 18:58-68, 1971. 
[11] B. Hevko, R. Hevko, O. Klendii, et al. Improvement of machine safety devices. Acta Polytechnica 58(1):17-25, 2018. DOI:10.14311/AP.2018.58.0017

[12] V. Goremikins, L. Blesák, J. Novak, F. Wald. Experimental method on investigation of fibre reinforced concrete at elevated temperatures. Acta Polytechnica 56(4):258-264, 2016. DOI:10.14311/AP.2016.56.0258

[13] G. Lin, J. Teng. Three-dimensional finite-element analysis of frp-confined circular concrete columns under eccentric loading. Journal of Composites for

Construction 21(4):04017003, 2017. DOI:10.1061/(ASCE)CC.1943-5614.0000772

[14] I. Mirsayapov, A. Tamrazyan. On calculation of reinforced concrete structures for endurance. Industrial and Civil Construction 11:19-23, 2016.

[15] F. Zamaliev, V. Filippov. Calculation-experimental studies of steel-reinforced concrete structures. Industrial and Civil Construction 7:29-36, 2015.

[16] E. A. Chystiakov, V. V. Surin. Bearing capacity of compressed reinforced concrete columns with

high-strength non-stressed reinforcement. Strength and deformation characteristics of elements of concrete and reinforced concrete structures 11:70-80, 1981.
[17] A. Basheerudeen, S. Anandan. Simplified mix design procedures for steel fibre reinforced self compacting concrete. Engineering Journal 19(1):21-36, 2015. DOI:10.4186/ej.2015.19.1.21.

[18] A. Kovrov, A. Kovtunenko, N. Vysochan. The effect of the loading order on the formation of the stress-strain state of the reinforced concrete frame structure. Tehnicki Glasnik-Technical Journal 10(3-4):98-101, 2016.

[19] T. Gernay. A method for measuring the sensitivity of building structural members to fire decay phases. Acta Polytechnica 56(5):344-352, 2016. DOI:10.14311/AP.2016.56.0344.

[20] C. Melendez, P. Miguel, L. Pallarés. A simplified approach for the ultimate limit state analysis of three-dimensional reinforced concrete elements. Engineering Structures 123:330-340, 2016. DOI:10.1016/j.engstruct.2016.05.039

[21] B. Golyshev, V. Bachynskyi, V. Polishchuk. Design of reinforced concrete structures. 1990. 